\title{
Individual Differences in Emotional Complexity: Their Psychological Implications
}

\author{
Sun-Mee Kang and Phillip R. Shaver \\ University of California, Davis
}

\begin{abstract}
Two studies explored the nature and psychological implications of individual differences in emotional complexity, defined as having emotional experiences that are broad in range and well differentiated. Emotional complexity was predicted to be associated with private selfconsciousness, openness to experience, empathic tendencies, cognitive complexity, ability to differentiate among named emotions, range of emotions experienced daily, and interpersonal adaptability. The Range and Differentiation of Emotional Experience Scale (RDEES) was developed to test these hypotheses. In Study $1(N=1,129)$ students completed questionnaire packets containing the RDEES and various outcome measures. Study $2(N=95)$ included the RDEES and non-self-report measures such as peer reports, complexity of representations of the emotion domain, and level of ego development measured by a sentence completion test. Results supported all of the hypotheses, providing extensive evidence for the RDEES's construct validity. Findings were discussed in terms of the role of emotional complexity in ego maturity and interpersonal adaptability.
\end{abstract}

Sun-Mee Kang, and Phillip R. Shaver, Department of Psychology, University of California, Davis.

This research was supported by the 2001 American Psychological Association Dissertation Research Awards to the first author. Portions of this research were presented at the 1st annual meeting of the Society for Personality and Social Psychology, Nashville, Tennessee, February 2000.

We are grateful to Richard W. Robins, Robert A. Emmons, Keith Widaman, Niels G. Waller, Xiaojia Ge, Jo Kung-Chiao Hsieh, and anonymous reviewers for their helpful comments on earlier versions of this article.

Correspondence concerning this article should be addressed to Sun-Mee Kang, who is now at Department of Psychology, California State University, 18111 Nordhoff Street, Northridge, CA 91330-8255. Electronic mail may be sent to skang@csun.edu.

Journal of Personality 72:4, August 2004.

Blackwell Publishing 2004 
Emotion is a difficult construct to define. Although the exact definition of emotion differs widely among researchers, there is general agreement that emotion consists of three distinct aspects: physiological arousal, emotional expression, and emotional experience (Malatesta \& Izard, 1984). The physiological arousal aspect has attracted attention from emotion researchers who followed the tradition of the James-Lange theory. Their efforts have been mainly focused on finding a distinct pattern of autonomic arousal associated with each emotion, and modest differences in autonomic arousal patterns are sometimes found (Levenson, 1992; but see Foster, Webster, \& Smith, 1997, and Stemmler, 1992). After the seminal research on emotional expression by Darwin (1872/1965), this objectively observable aspect of emotion has been intensively studied. Accumulated research on emotional expression has contributed not only to understanding the functions of verbal and nonverbal expression but also to documenting the universal and cross-cultural aspects of emotional expression (Ekman \& Friesen, 1975; but see Russell, 1995).

Compared to arousal and expression, emotional experience is the most explored, but the least understood, aspect of emotion. Since emotional experiences are feelings that people have in their everyday life, numerous tests have been developed and used to measure not only a specific emotion (e.g., depression, anxiety, or anger) but also transient and long-lasting, "trait-like" global mood states (e.g., Watson, Clark, \& Tellegen, 1988). Moreover, if we consider that most personality scales assess some aspects of emotional experience, it is legitimate to say that emotional experience is the most extensively sampled emotional component. However, it is also the least understood component because we still do not know how emotional experiences are created and where their physiological underpinnings are located in the brain.

Although research on the emotion lexicon (Clore, Ortony, \& Foss, 1987; Shaver, Schwartz, Kirson, \& O’Conner, 1987), affect intensity (Larsen, Diener, \& Emmons, 1986), and underlying dimensions of affect (Feldman Barrett \& Russell, 1998; Watson \& Tellegen, 1985) has contributed to understanding the structure of emotional experience, less attention has been paid to exploring individual differences in the range and differentiation of emotional experience. It is obviously difficult for observers to know how an observed individual experiences emotion, but several empirical perspectives on individual differences in emotional experience have been developed. 
For example, the concept of alexithymia grew out of clinical observations of psychosomatic patients (Sifneos, 1973), many of whom seem to have difficulty characterizing their emotional experiences (Taylor, Bagby, \& Parker, 1991). A defining feature of alexithymic patients is that "they know very little about their own feelings" (Taylor et al., 1991, p. 155), a deficiency that led Freedman and Sweet (1954) to call them "emotional illiterates (p. 366)." It has been suggested that alexithymia is a manifestation of limited and undifferentiated emotional experience (Lane, et al., 1996; Nemiah \& Sifneos, 1970). This claim raises an intriguing issue: Is there a larger spectrum of individual differences in range and differentiation of emotional experience? Although alexithymia may be an extreme case of limited and undifferentiated emotional experience, it is possible that range and differentiation of emotional experience are continuously varying qualities of experience, which, at some level, apply to everyone. If so, why do these individual differences exist and what are the psychological and behavioral implications of having varied and well-differentiated emotional experiences?

The purpose of our research is to explore the psychological significance of individual differences in emotional complexity, which was conceptualized as having two correlated aspects: (1) a broad range of emotional experiences and (2) a propensity to make subtle distinctions within emotion categories. The first aspect is related to the range or span of different emotions experienced by a particular person. The second aspect concerns how well a person can distinguish subtle differences among similar emotions. This state of emotional complexity can be visualized as a tree with many branches, each of which, in turn, has many twigs. Under this conceptualization, we will argue that (1) emotional complexity is a product of cognitive complexity, personality dispositions, and life experiences, and (2) emotional complexity leads to empathic understanding of others' feelings and greater interpersonal adaptability.

To address these new initiatives, we will review the theoretical background of these individual differences and related constructs, including affective complexity, levels of emotional awareness, and emotional range.

\section{Affective Complexity}

Several explanations of individual differences in emotional complexity have been proposed. Depending on theoretical orientations, these 
individual differences are viewed as a dispositional trait or a reflection of different levels of cognitive ability.

A dispositional account of individual difference can be traced back to Wessman and Ricks's pioneering study (1966). They noticed that people differed in richness and diversity of subjective feelings and coined the term "affective complexity" to name the individual differences. To quantify the individual differences, Wessman and Ricks used $P$-factor analysis (Cattell, 1952), which involves the application of ordinary factor-analytic procedures to data generated by each individual in a sample. Wessman and Ricks reasoned that a person with a more differentiated and complex emotional life would exhibit less covariation among emotion states. But since Wessman and Ricks's initiative, research on affective complexity using this methodology has been rather sparse (e.g., Carstensen, Pasupathi, Mayr, \& Nesselroade, 2000; Feldman, 1995; Feldman Barrett, 1998; Feldman Barrett, et al., 2001; Larsen \& Cutler, 1996; Tobacyk, 1981; Zevon \& Tellegen, 1982), probably because of the high cost of employing $P$-factor analysis, reliability of the resulting measures, and mixed results generated by them.

Among the investigators in this tradition, Feldman Barrett distinguished herself from others by approaching individual differences based on her model of affective structure (Feldman Barrett \& Russell, 1998). Rather than relying on global individual differences in affective complexity, she was interested in individual differences in two dimensions of affective structure, valence focus and arousal focus. She postulated that these two dimensions would have different effects on the experience of discrete emotions. That is, individuals high in valence focus and low in arousal focus tend to experience global pleasant or unpleasant states rather than discrete emotions. The data from 56 college students provided preliminary support for these hypotheses (Feldman Barrett, 1998).

\section{Cognitive Complexity}

Individual differences in emotional complexity were also explained by cognitively oriented theories of emotional experience. Lane and Schwartz (1987) were among the first to present a cognitive-developmental model of emotional awareness. Based on Piaget's (1962) cognitive-developmental theory, Lane and Schwartz assumed that emotional experience develops according to the same principles as 
cognitive development. They argued that individual differences in emotional awareness reflect variation in the cognitive complexity of recognizing and describing emotion in oneself and others. To measure individual differences in level of emotional awareness, Lane and his colleagues created a projective test called the Levels of Emotional Awareness Scale (LEAS; Lane, Quinlan, Schwartz, Walker, \& Zeitlin, 1990). Although Lane and Schwartz's developmental stage model is intriguing and potentially useful, the data from a large-scale study with various age groups (Lane, Sechrest, \& Riedel, 1998) showed a negative association between age and levels of emotional awareness $(r=-.24)$, implying that one of the key predictions from the model was not empirically supported.

Sommers (1981) introduced another cognitive approach to individual differences in emotional experience. She posited that individual differences in social cognitive skills would lead to differences in emotional responsiveness in a given situation. She developed a test to measure what she called "emotional range." The test asks research participants to read a short description of a situation and to elaborate the story in terms of emotional experiences the characters might have. An individual's emotional range was defined as the number of different emotions he or she mentions in the descriptions. Sommers and her colleagues reported preliminary evidence for the scale's validity (Sommers, 1981; Sommers \& Scioli, 1986), suggesting that people with advanced social cognitive complexity tend to have more varied emotional experiences. ${ }^{1}$

Three conclusions can be drawn from this brief literature review. First, existing research suggests that individuals with relatively complex emotional experiences are likely to be cognitively sophisticated in certain respects. Beyond these generalizations, however, the field is still lacking a comprehensive picture of individuals with complex emotional experience. Second, little is known about the psychological implications of emotional complexity. Third, researchers in this field may need a simpler, more reliable, more easily scored measure of the construct. In the following sections, we address these issues.

1. Unfortunately, Sommers died shortly after completing her pioneering research, so it was not followed up as extensively as it might otherwise have been. For one interesting study based on an elaboration of her test, see Ben-Artzi and Mikulincer (1995). 


\section{Personality Characteristics, Life Experiences, and Complex Emotional Experience}

Why do some people experience more varied and well-differentiated emotions than other people? Previous research implies that individual differences in cognitive complexity could be one explanation. However, less attention has been paid to other factors that may also be important in fostering varied and well-differentiated emotional experiences. Our literature review identified two potentially important personality characteristics: private self-consciousness and Openness to Experience.

Private self-consciousness is one aspect or facet of self-consciousness and is considered to be a stable personality trait (Fenigstein, Scheier, \& Buss, 1975). It is defined as a tendency to be aware of the internal aspects of self and to be particularly attentive to inner thoughts and feelings (Fenigstein, 1997). Individuals high on this dimension tend to be more responsive to their transient affective states (Fenigstein et al., 1975). We speculated that private self-consciousness would be a core quality for having emotional complexity, because emotional experiences require that a person attend to both inner changes and outer situations. Emotional experience is characterized as a subjective feeling, based on interpretation and evaluation of perceived situations and physiological arousal (Lewis, 1993). Without attention, a person may not have an emotional experience, although physiological arousal and provocative situations may exist (Lewis, 1993). This analysis suggests that if someone has unusually rich emotional experiences, he or she will also be someone who pays more attention than usual to feelings.

Another personality trait that could foster complex emotional experience is Openness to Experience. One of the so-called Big Five personality traits, Openness to Experience is characterized by active imagination, aesthetic sensitivity, preference for variety, intellectual curiosity, and independence of judgment (McCrae \& Costa, 1997). Individuals high on this trait dimension appear to welcome change and seek new experiences (McCrae \& Costa, 1997). Because emotion researchers speculate that the acquisition of new experiences contributes to the elaboration of emotional life (De Rivera, 1984; Lewis, 1993), individuals with this personality trait are more likely to have opportunities to develop emotional complexity based on their diverse life experiences (Zhiyan \& Singer, 1997). 
This speculation has been partially supported by empirical evidence: A strong negative correlation $(r=-.49)$ between Openness to Experience and the 20-item Toronto Alexithymia Scale (TAS) was reported (Bagby, Taylor, \& Parker, 1994). Since the TAS is thought to measure a very limited and poorly differentiated state of emotional experience, the strong negative association between alexithymia and Openness to Experience supports the idea that there should be a connection between emotional complexity and Openness to Experience. We therefore hypothesized that attention to feelings and Openness to experience would be associated with rich emotional experiences.

\section{Implications of Emotional Complexity}

What might be the psychological implications of having emotional complexity? As a consequence of experiencing varied and differentiated emotions, a person might be expected to show greater empathic understanding of others. This is because understanding others often requires that we understand their feelings in a particular situation (De Rivera, 1984). Emotion can deliver dense information about what transpires in others' minds during an interpersonal situation. In order to understand others' feelings, individuals may benefit from having their own broad repertoire of emotional experiences because understanding others' feelings is presumably based partly on understanding one's own (Saarni, 1997).

We also reasoned that emotional complexity would enhance interpersonal adaptability because knowing others' feelings in interpersonal situations provides useful information about how to react to them. In other words, empathic understanding of others' feelings should increase the likelihood of choosing appropriate responses or reactions. There is empirical support for this argument. Clinical observers have often reported poor interpersonal relationships among alexithymic patients (Lumley, Stettner, \& Wehmer, 1996). It has been argued that undifferentiated emotional experience and poor emotional expressivity may cause such patients to have fewer close relationships and less social support. Lopez et al. (1997) also found that securely attached individuals differentiated significantly more between two emotions, shame and guilt, than did insecurely attached people. According to Lopez et al., securely attached individuals may respond to interpersonal problems more appropriately based 
on their ability to make finer-grained distinctions between the two emotions.

In fact, emotion researchers have speculated about the possible contribution of rich emotional experiences to interpersonal adaptability. For example, Lane and Schwartz (1992, p. 5) said, "Consistent with this greater capacity for awareness of the emotions of self and other, there is increased flexibility in interpersonal interactions and greater adaptational success." According to Feldman Barrett, Lane, Sechrest, and Schwartz (2000), "It seems likely that greater emotional complexity is associated with greater adaptation to the environment" (p. 1034). Beyond speculations, however, there has been no empirical attempt to explore the association between emotional complexity and interpersonal adaptability. The present study was the first to test the hypothesis that individuals with varied and differentiated emotional experience would be more adaptable in interpersonal interactions.

\section{Emotional Complexity and Emotional Intelligence}

Finally, it is important to consider how emotional complexity is related to the popular construct "emotional intelligence." In their recently revised definition of emotional intelligence, Mayer and Salovey (1997) described it as consisting of four mental abilities: ability to perceive emotions in oneself and others, ability to access and generate emotions so as to assist thought, ability to understand emotions and emotional knowledge, and ability to regulate emotions reflectively so as to promote emotional and intellectual growth. According to this conceptualization, emotional intelligence does not focus on individual differences in the range and differentiation of emotional experience. Rather, the essence of emotional intelligence is the ability to use emotional information and regulate moods. However, one facet of emotional intelligence - ability to identify one's own emotions - seems to be directly related to emotional complexity. Individual differences in this ability may lead to individual differences in complex emotional experience.

In summary, we hypothesized that individuals with more complex emotional experience would be more attentive to their feelings, more open to experience, better able to understand others' feelings, and better adjusted socially. To test these hypotheses in Study 1, it was necessary to develop the Range and Differentiation of Emotional Experience Scale (RDEES). 


\section{Study 1}

The main purpose of this study was to create the RDEES and begin to evaluate its construct validity. A series of three questionnaire studies (based on what we will call Samples 1, 2, and 3 of Study 1) were conducted. While refining the RDEES in successive trials, we explored its associations with other measures of emotional complexity, alexithymia, emotional intelligence, emotional expressiveness, and emotional intensity to locate emotional complexity in a nomological network (Cronbach \& Meehl, 1955) of emotion constructs. Four major hypotheses were tested: The RDEES would be positively associated with measures of (1) private self-consciousness, (2) Openness to experience, and (3) empathic ability. It would also be positively associated with (4) measures of interpersonal adjustment.

\section{METHOD}

\section{Participants and Procedure}

Sample 1 consisted of 400 students from introductory psychology classes. Participants in Sample $2(N=629)$ and Sample $3(N=100)$ were drawn from a variety of psychology courses. A packet of questionnaires was completed in small group sessions for extra credit. All participants ranged in age from 17 to 51 , with a mean age of 19.6 years $(S D=2.38)$. Seventyfour percent of the students were female, and a majority were either Asian American (43\%) or European American (42\%).

\section{Development and Refinement of the RDEES}

Sixteen items were initially generated to tap emotional complexity, eight items for Range (i.e., breadth of emotional experience) and eight for Differentiation, and used in Sample 1. Students rated each item on a 5-point scale, with 1 indicating that it "does not describe me very well" and 5 indicating that it "describes me very well."

Before an exploratory factor analysis was conducted, three items were deleted because of low item-total (subscale) correlations. Responses to the remaining 13 items were subjected to a principal axis factor analysis. Based on the scree plot, two factors (clearly representing the subconstructs of range and differentiation) were retained and rotated using the oblique criterion. Five items were eliminated because either their factor loadings were less then .40 or they loaded on both factors. The alpha coefficient for the RDEES was .75, with .75 for the 4-item Range subscale and .71 for the 4-item Differentiation subscale. Although the scale as a 
whole had acceptable internal consistency for its length, an additional eight items were developed to increase internal consistency and were included in the second phase of the refinement process.

The second phase of item and factor analyses was based on the 629 participants in Sample 2. Two items were dropped in this process because their factor loadings were lower than .40. The resulting 14-item RDEES had a mean inter-item correlation of .30 , with correlations ranging from .05 to .64 . The final factor analysis yielded the same two factors found in the preliminary studies and accounted for $41 \%$ of the total variance. The two factors were named "Range" and "Differentiation" and served as the basis for constructing two subscales. The alpha coefficient of the 14-item RDEES was .85, (.82 for the 7-item Range subscale and .79 for the 7-item Differentiation subscale). The correlations between the two subscales ranged from .30 to .47 (see Table 2). The final version of the RDEES is displayed in Table 1 along with a summary of descriptive statistics and a factor analysis.

We noticed that the score distribution for the Range subscale was somewhat negatively skewed (skewness $=-.56$ ). To reduce this skewness, we explored the benefits of a 7-point rather than a 5-point answer continuum while providing a more extreme anchor for the higher end of the scale (describes me extremely well rather than describes me very well) in Sample 3. Although item and factor analyses replicated the two-factor structure of the RDEES, the distribution of the Range scores still remained slightly negatively skewed (skewness $=-.28$ ). Correlations between the 8-item RDEES scores and the 14-item RDEES scores were .93 (Sample 2) and .95 (Sample 3).

\section{Materials}

The three questionnaire studies (Samples 1, 2, and 3) shared many common measures, but some scales were used on only one or two occasions. The scales used in each sample can be found in Table 2, 3, and 5, along with their alpha coefficients based on the samples in Study 1.

Emotion measures. Sommers' Emotional Range Test (ERT; Sommers, 1981) and the Levels of Emotional Awareness Scale (LEAS; Lane et al., 1990) were administered to explore the concurrent validity of the RDEES. The ERT consists of a brief description of three situations that subjects are asked to elaborate on, focusing on the characters' likely feelings. The responses were scored by one rater trained by the first author. Interrater reliability between the rater and the author was .90 , based on the responses from 40 randomly selected students. The average number of emotion words used per situation was $3.21(S D=1.31)$.

We used two split-half versions of the original 20-item LEAS (Form A and Form B) because of time constraints. Fifty students received Form A 


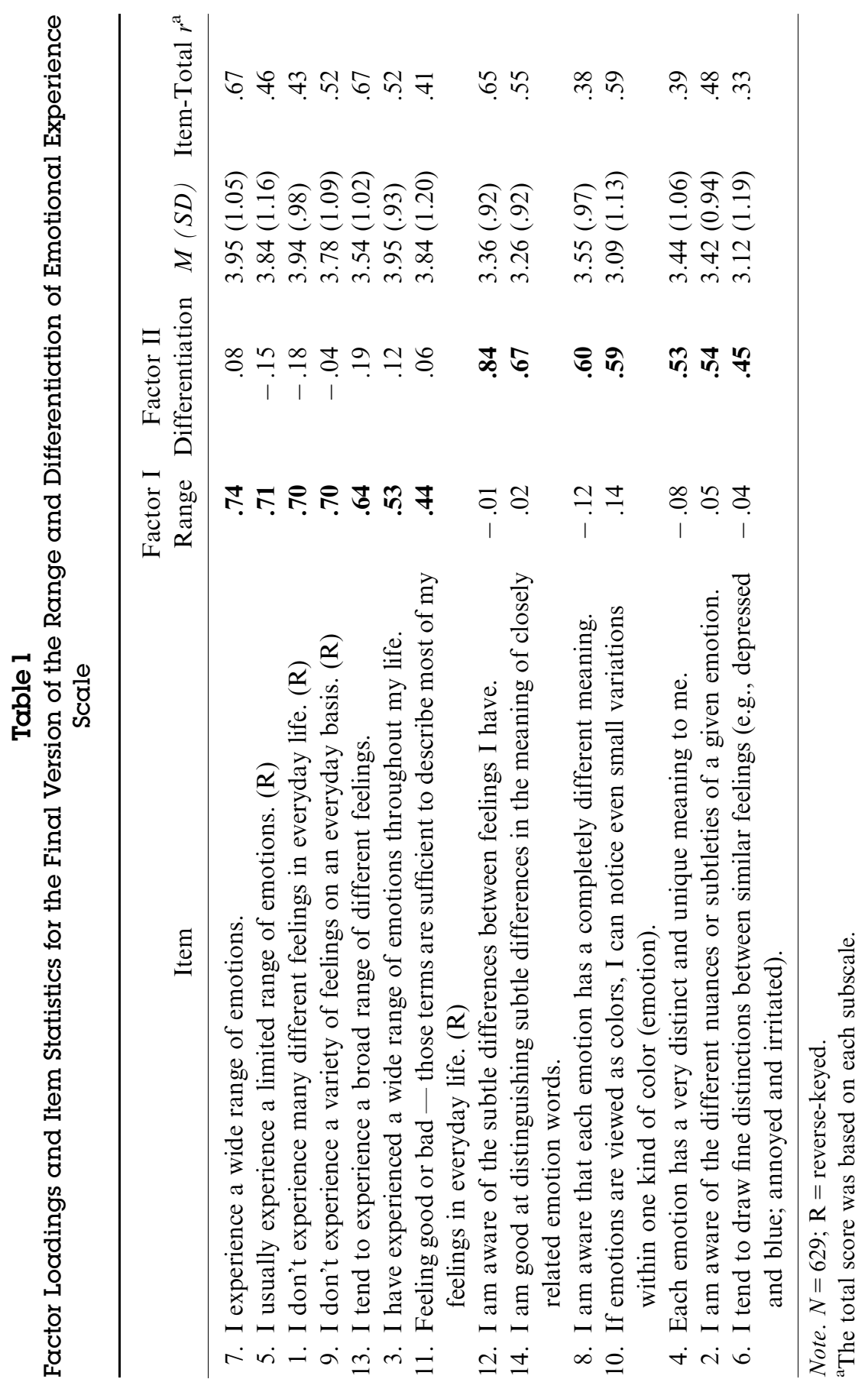


and the other fifty, Form B. Two raters scored the LEAS independently after mastering a scoring manual and correctly classifying sample responses. The interrater reliability was .82 , and all discrepancies were resolved by discussion. The mean score was $29.5(S D=4.24)$ for Form A and $31.56(S D=3.54)$ for Form B. Because the two different forms of the LEAS were employed to cover all original 20 items, all scores were standardized within each subsample before combining them. Whenever any statistics involved in the LEAS were computed, other scales were also standardized within each subsample.

Four emotion scales were used in all three studies to explore how emotional complexity is associated with other emotion concepts. The 16-item Emotional Expressiveness Questionnaire (EEQ; King \& Emmons, 1990) measures self-reported emotional expressiveness. The 40-item Affect Intensity Measure (AIM; Larsen et al., 1986) was designed to measure the characteristic intensity of emotional experience. The 20-item Toronto Alexithymia Scale (TAS; Bagby, Parker, \& Taylor, 1994) assesses difficulty identifying feelings, difficulty describing feelings, and externally oriented thinking. The Trait Meta-Mood Scale (TMMS; Salovey, Mayer, Goldman, Turvey, \& Palfai, 1995) measures individual differences in attention to moods and feelings, the clarity with which these feelings are experienced, and beliefs about how to regulate them. This scale was developed to assess an early conceptualization of "emotional intelligence" (Salovey \& Mayer, 1990) and was employed here to examine the association between emotional complexity and identifying one's own emotions. ${ }^{2}$

Measures used for testing the major hypotheses. The Self-Consciousness Scale (SCS; Fenigstein et al., 1975) was used to measure private self-consciousness, public self-consciousness, and social anxiety. The NEO FiveFactor Inventory (NEO-FFI; Costa \& McCrae, 1989) and the Big Five Inventory (BFI; John \& Srivastava, 1999) were employed to assess five major domains of personality: Openness to Experience, Extraversion, Neuroticism, Conscientiousness, and Agreeableness. A subscale of the Interpersonal Reactivity Index (Davis, 1980) was selected to measure empathy; the 7-item Empathic Concern (EC) subscale measures the tendency to experience feelings of warmth, compassion, and concern for others.

Four scales were used to measure interpersonal adaptability. The 13item Revised Self-Monitoring Scale (RSMS; Lennox \& Wolfe, 1984) taps

2. Although an earlier version of the Multifactor Emotional Intelligence Scale (MEIS; Mayer, Caruso, \& Salovey, 2000) was available when we conducted Study 1, we selected the Trait-Meta Mood Scale because we hypothesized that perceiving one's own emotions would be related to individual differences in the range and differentiation of emotional experience. The MEIS was not designed to assess ability to perceive one's own emotions. 
two characteristics of high self-monitoring individuals: ability to modify self-presentation and sensitivity to the expressive behavior of others. Another adaptability measure was the Battery of Interpersonal Capabilities (BIC; Paulhus \& Martin, 1987), which uses 7-point scales to assess a person's ability to adjust his or her behavior to the interpersonal demands of a wide range of situations. The scale includes 16 interpersonal attributes that are either socially desirable (e.g., "gregarious") or socially undesirable (e.g., "aloof"). Respondents are asked about their ability to enact each of these interpersonal attributes. For example, "How capable are you of being aloof when the situation requires it?" The scale contains 5 positive adjectives and 11 negative adjectives describing social behaviors. We used only part of the scale in this study because we failed to replicate the factor structure reported by Paulhus and Martin (1987). We obtained two factors: positive versus negative behaviors in interpersonal situations. Only the 5-item positive behavior subscale (henceforth called the positive BIC) was considered because only it had a correlation with the RSMS in Sample 2 ( $r=.31$ vs. $r=.08$ for the negative behavior subscale).

Two additional scales were also developed especially for this study. A 5-item Sensitivity to Others' Feelings scale (SOF), was created for Sample 1 , which is rated on a 5-point scale (a sample item, "When my friends talk to me, I notice how their emotions change from moment to moment including very subtle changes in emotions."). Its alpha coefficient was .74. The Interpersonal Relationship Quality (IRQ) scale was developed to measure quality of interpersonal relationships, describing warm and comforting relationships. Sample items are "I feel that my relationships with others are friendly and comforting" and "I enjoy visiting old friends and neighbors in my hometown." All items were rated on a 5-point scale ranging from 1 (does not describe me at all) to 5 (describes me very well). The psychometric properties of the IRQ implied that it was a sound measure of interpersonal relationship quality; the internal consistency reliability was .80 ; the test-retest reliability for a 6 -week interval was .78 $(N=93)$; the self-peer agreement $(N=94)$ was .56 (refer to Study 2 for a more detailed description regarding peer ratings); its correlation with the Revised Self-Monitoring Scale was .32.

Social desirability and academic achievement. Several other measures were administered to control potentially confounded variables and provide more information about the RDEES. The 33-item Marlowe-Crowne Social Desirability Scale (MCSD; Marlowe \& Crowne, 1964) and the 40item Balanced Inventory of Desirable Responding (BIDR; Paulhus, 1984) were selected to assess social desirability response set. The BIDR contains two subscales measuring impression management and self-deception. Subjects were also asked either to report their SAT scores and cumulative GPA (in Sample 1) or for permission to access those scores from 
official school records (in Sample 2). A total of 536 participants in Sample 2 signed the consent form, and it was possible to retrieve the records of 449 of them. (The others were inaccessible because of inaccurate information on the permission form.)

\section{RESULTS AND DISCUSSION}

\section{Gender Differences, Ethnic Differences, and Social Desirability}

Many scales assessing emotional expressiveness or emotional intensity yield gender differences (e.g., King \& Emmons, 1990; Larsen, 1987) and ethnic differences (e.g., Kitayama \& Markus, 1994). We therefore checked for gender and ethnic differences in the RDEES before proceeding to further analyses. The means and standard deviations for men and women in the three samples are displayed in Table 2, along with Pearson correlation coefficients with gender (women were coded as 1 and men as 0) and ethnicity (Asian Americans were coded as 0 and European Americans as 1). Although women and European Americans tended to have slightly higher scores than men and Asian Americans on the RDEES, the differences were not large. Correlations between scores on the RDEES and scores on social desirability scales were also examined. In Sample 1, the correlation between the RDEES and the Marlowe-Crowne Social Desirability scale was $-.01(r=-.12$ for the Range subscale and $r=.11$ for the Differentiation subscale). In Samples 2 and 3, the two subscale scores of the Balanced Inventory of Desirable Responding (BIDR) were only slightly positively correlated with the RDEES $(r \mathrm{~s}=.15$ and .03 for self-deception and $r \mathrm{~s}=.09$ and .08 for impression management). The Range subscale was not associated with the BIDR $(r \mathrm{~s}=.10, .03$ for impression management and $r \mathrm{~s}=.03,-.11$ for self-deception), but the Differentiation subscale was somewhat related to it $(r \mathrm{~s}=.22$ and .27 for self-deception and $r \mathrm{~s}=.06$ and .14 for impression management). None of these coefficients suggests that the RDEES subscales simply measure social desirability biases.

\section{Concurrent and Discriminant Validity of the RDEES}

To establish preliminary construct validity for the RDEES, correlations among scores on the RDEES, Sommers' Emotional Range Test (ERT), and the Levels of Emotional Awareness Scale (LEAS) 


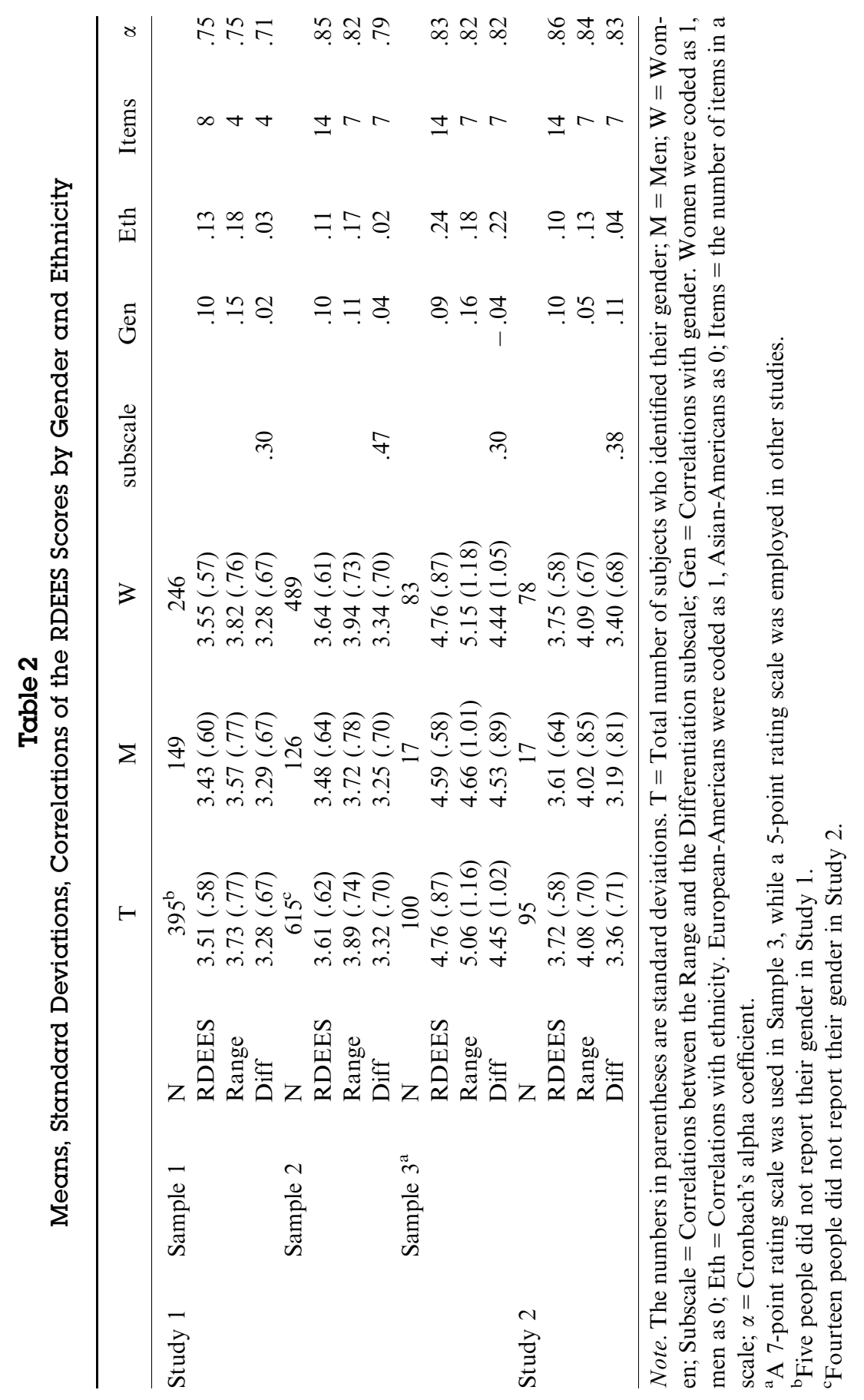


were examined. The results are displayed in Table 3, along with properties of the scales. Although the RDEES was not highly correlated with either the ERT $(r=.20)$ or the LEAS $(r=.30)$, the correlations were among the highest correlations involving the ERT and the LEAS. The low correlations can be attributed in part to nonshared method variance because the ERT and the LEAS require open-ended responses. It is not clear, however, why the LEAS did not have higher correlations with conceptually related measures (e.g., the Toronto Alexithymia Scale; $r=-.17$ ) than with other emotion scales (e.g., the Affect Intensity Measure; $r=.24$ ). The ERT and the LEAS also had somewhat low internal consistency coefficients ( $\alpha=.68$ and .63 , respectively), but this was attributable mainly to their brevity.

The correlations between the ERT and the two subscales of the RDEES further supported the construct validity of the RDEES, showing that the Range subscale was more related to the ERT $(r=.21)$ than the Differentiation subscale $(r=.10)$. Both subscales of the RDEES were correlated with the LEAS $(r=.27$ for Range and $r=.22$ for Differentiation), implying that emotional awareness encompasses both aspects of emotional experience assessed by the RDEES.

We predicted that the RDEES and the Toronto Alexithymia Scale (TAS) would be negatively correlated, and they were $(r \mathrm{~s}=-.38$, -.36 , and -.38 in Samples 1, 2, and 3, respectively). The RDEES was also substantially correlated with the Trait-Meta Mood Scale (TMMS; $r \mathrm{~s}=.47, .46$, and .54), an emotional intelligence scale. Indeed, the RDEES was positively associated with the Clarity scale, one of the subscales of the TMMS $(r \mathrm{~s}=.26, .27$, and .37$)$, implying that clearly identifying one's own emotions is related to individual differences in the range and differentiation of emotional experience. The correlation between the TAS scores and the TMMS scores was very high $(r \mathrm{~s}=-.63,-.73$, and -.73$)$, implying that the TAS and the TMMS tap the same or overlapping constructs. To locate the RDEES in a nomological network of emotion constructs, we examined its correlations with two other scales measuring important aspects of emotion. The RDEES was positively correlated with both the Emotional Expressiveness Questionnaire $(r \mathrm{~s}=.42, .32$, and .45$)$ and the Affect Intensity Measure $(r \mathrm{~s}=.25, .32$, and .30$)$, but the magnitudes of the correlations indicated that the RDEES was not simply redundant with measures of emotional expressivity and intensity. 


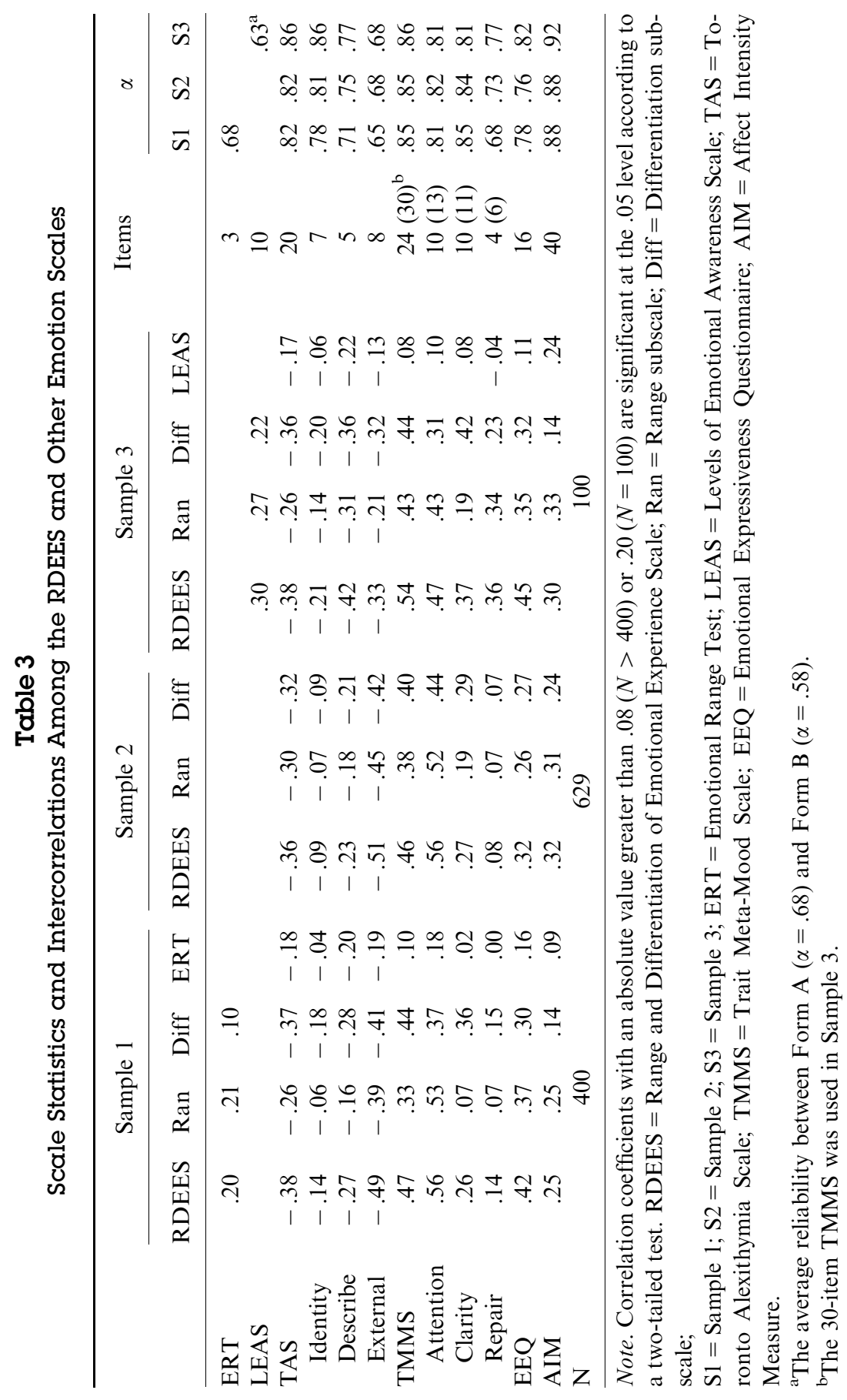


Although the two subscales of the RDEES did not differ much in their associations with other emotion scales, the Range subscale was more strongly associated with emotional intensity $(r s=.25, .32, .33$, compared to $r \mathrm{~s}=.14, .24, .14$ for the Differentiation subscale), and the Differentiation subscale was more tightly connected with the Clarity scale, one of the subscales of the TMMS ( $r \mathrm{~s}=.36, .29, .42$, compared to $r \mathrm{~s}=.07, .19, .19$ for the Range subscale). These findings indicate that individuals with emotional differentiation tend to know clearly what feelings they experience, while people with a broad range of emotion have a propensity to experience intense feelings. We should mention here that the associations between the RDEES and other emotion scales cannot be attributed to a direct overlap in items between the RDEES and the other emotion measures. As displayed in Table 1, the items of the RDEES are not similar to items in the TAS, the TMMS, the EEQ, and the AIM.

Finally, three separate principal axis factor analyses were performed on all of the emotion variables to explore how they load on higher-order factors. Emotional expressivity, emotional intensity, the three subscales of the TAS (identifying feelings, describing feelings, and externally oriented thinking), and the three subscales of the TMMS (attention, clarity, and repair) were entered into the factor analyses, along with the Range and Differentiation subscales. The three subscales of the TAS were reverse-keyed before performing factor analyses. Across the three factor analyses, all 10 emotion variables loaded positively on the first unrotated variable, implying that there is one general emotion, or emotionality, factor. Based on the scree plot, two factors were extracted each time. The overall pattern found in Sample 1 was replicated in Samples 2 and 3 with several specific exceptions. The first factor includes expressivity, intensity, attention, range, differentiation, and externally oriented thinking, and the second factor encompasses clarity of feelings, describing feelings, identifying feelings, and mood repair. Interestingly, differentiation, externally oriented thinking, and mood repair somewhat unstably loaded on the factors. Differentiation loaded on both factors in Sample 1 and 3, and externally oriented thinking and mood repair were loaded on either the first or the second factor depending on the sample. This may mean that these three emotion variables are involved in both aspects of emotion (experiencing and recognizing emotions). 


\section{Construct Validity of the RDEES}

We hypothesized that individuals scoring higher on the RDEES would be more attentive to feelings, open to experience, empathic, and adjusted to interpersonal relationships. Table 4 displays the results. As expected, the RDEES was positively correlated with only one subscale of the SCS, the Private SCS ( $r=.38, .41$, and .33). The other two subscales, the Public SCS ( $r=.09$ and .05$)$ and the Social Anxiety scale $(r=-.10$ and -.14$)$, were not correlated significantly with the RDEES. The ERT was not related to any subscales of the SCS, whereas the LEAS was somewhat related to the Private SCS $(r=.21)$.

The RDEES was positively correlated with the Emotional Concern scale $(r=.35, .28$, and .23$)$, the measure of empathy. The ERT was also correlated significantly with empathy $(r=.20)$, but the LEAS was not $(r=.10)$. The prediction that the RDEES would be correlated with Openness to Experience was supported $(r=.42, .43$, and .40). The ERT was not correlated with any of the personality scales, but the LEAS was slightly associated with both Neuroticism $(r=.15)$ and Extraversion $(r=.19)$. The two subscales of the RDEES more or less replicated the same pattern of correlations with personality variables displayed by the RDEES as a whole.

The fact that the RDEES (and its two subscales) had no association with neuroticism is interesting. It suggests that having complex, well-differentiated emotional experience is independent of negative emotionality, whereas alexithymia is not. In fact, the discriminant validity of the Toronto Alexithymia scale has been questioned mainly because of its high correlations with measures of negative affect (Linden, Wen, \& Paulhus, 1995). In contrast, individuals who score high on the RDEES can experience either high or low levels of negative affect.

Associations of the RDEES with measures of academic achievement were examined to rule out the possibility that the RDEES simply measures cognitive ability. Although the RDEES and its subscales did not correlate with the quantitative SAT score or cumulative college GPA, they were somewhat correlated with the verbal SAT score $(r=.17, .18$ for the RDEES, .19, .22 for the Range subscale, and $.12, .09$ for the Differentiation subscale). ${ }^{3}$

3. We re-ran all of the analyses reported here after partialing out the effect of the verbal SAT score. This did not significantly affect any of the results. 


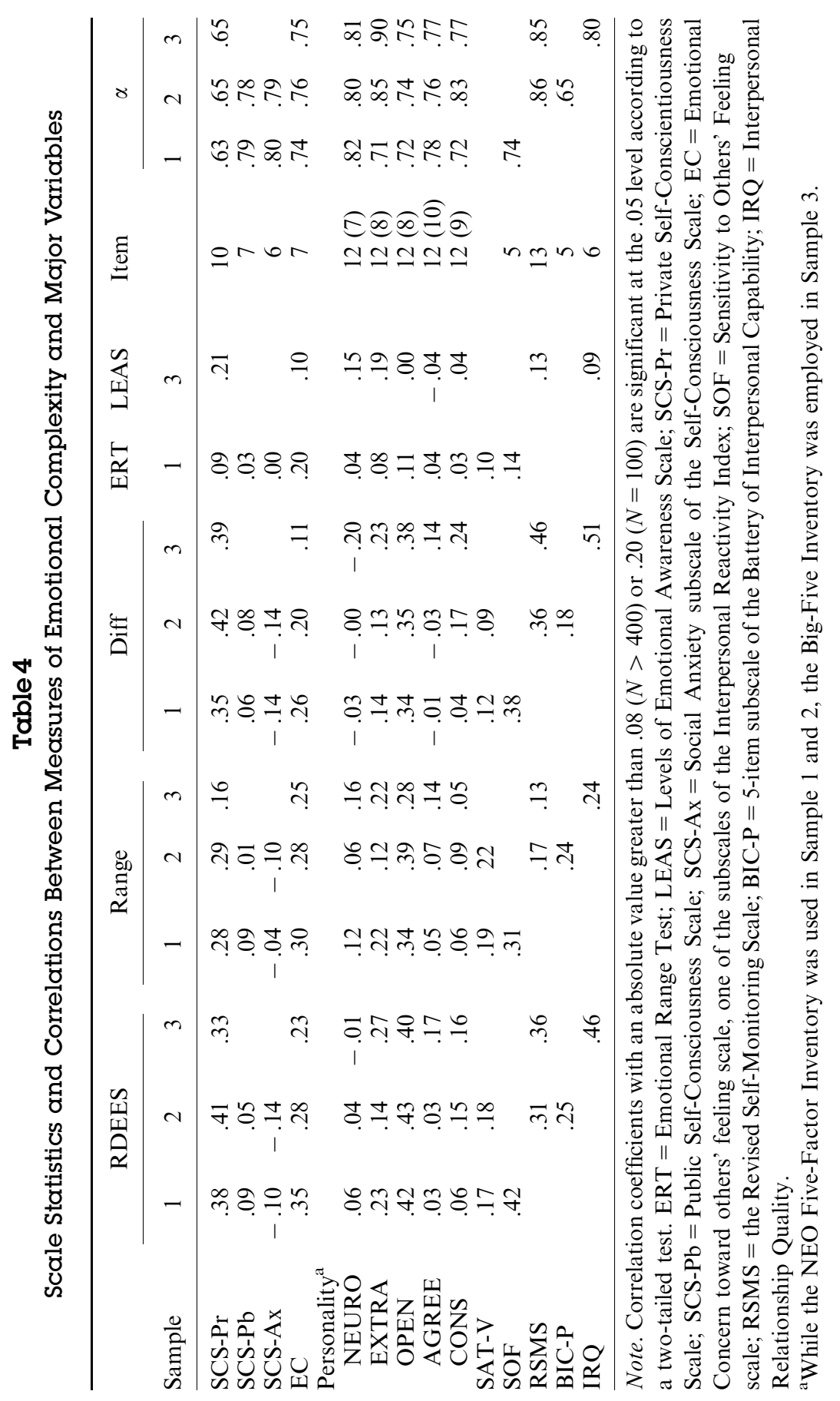




\section{Interpersonal Adaptability and the RDEES}

Four measures were used to examine the hypothesis that higher RDEES scores would be associated with interpersonal adaptability: Sensitivity to Others' Feelings (SOF) in Sample 1, the Revised SelfMonitoring Scale (RSMS) and the Battery of Interpersonal Capabilities (BIC) in Sample 2, and the RSMS and the Interpersonal Relationship Quality scale (IRQ) in Sample 3.

The bottom part of Table 4 displays the zero-order correlations among the indices of interpersonal adaptability and the emotional complexity scales. The RDEES and its two subscales were positively related to the measures of interpersonal adaptability. However, other emotion scales - especially the EEQ, the TAS, and the TMMSwere also more or less associated with interpersonal adaptability, as shown in Table 5. Since all of the emotion scales were correlated with each other, hierarchical regression analysis was applied to determine which variables accounted for unique variance in the measures of interpersonal adaptability.

Before conducting the hierarchical regression analysis, we created composite scores for interpersonal adaptability by averaging the standardized scores of the items from the RSMS and the positive BIC in Sample 2 and the RSMS and the IRQ in Sample 3. The alpha coefficients of the composite scores were .83 (Sample 2) and .84 (Sample 3). Zero-order correlation coefficients between the independent variables and the dependent variables, standardized regression coefficients with their $t$-values, and percentages of the variance explained by the regression equations are displayed in Table 5.

The regression analysis was conducted in two steps. In the first step, we simultaneously entered emotion scores and two control variables, gender and social desirability. At this stage, two major predictors emerged across the three samples - the measures of social desirability (Marlowe-Crowne Social Desirability scale in Sample 1 and the Self-Deception Scale of the BIDR in Samples 2) and the RDEES. The TAS and the EEQ appeared once each as a key predictor in Sample 1 and Sample 2, respectively, but their effects did not replicate with different outcome variables in other samples. The TMMS did not contribute at all, although its zero-order correlations with the outcome variable were substantial $(r s=.44, .30, .53)$. The emergence of the Self-Deception Scale as a strong predictor was 


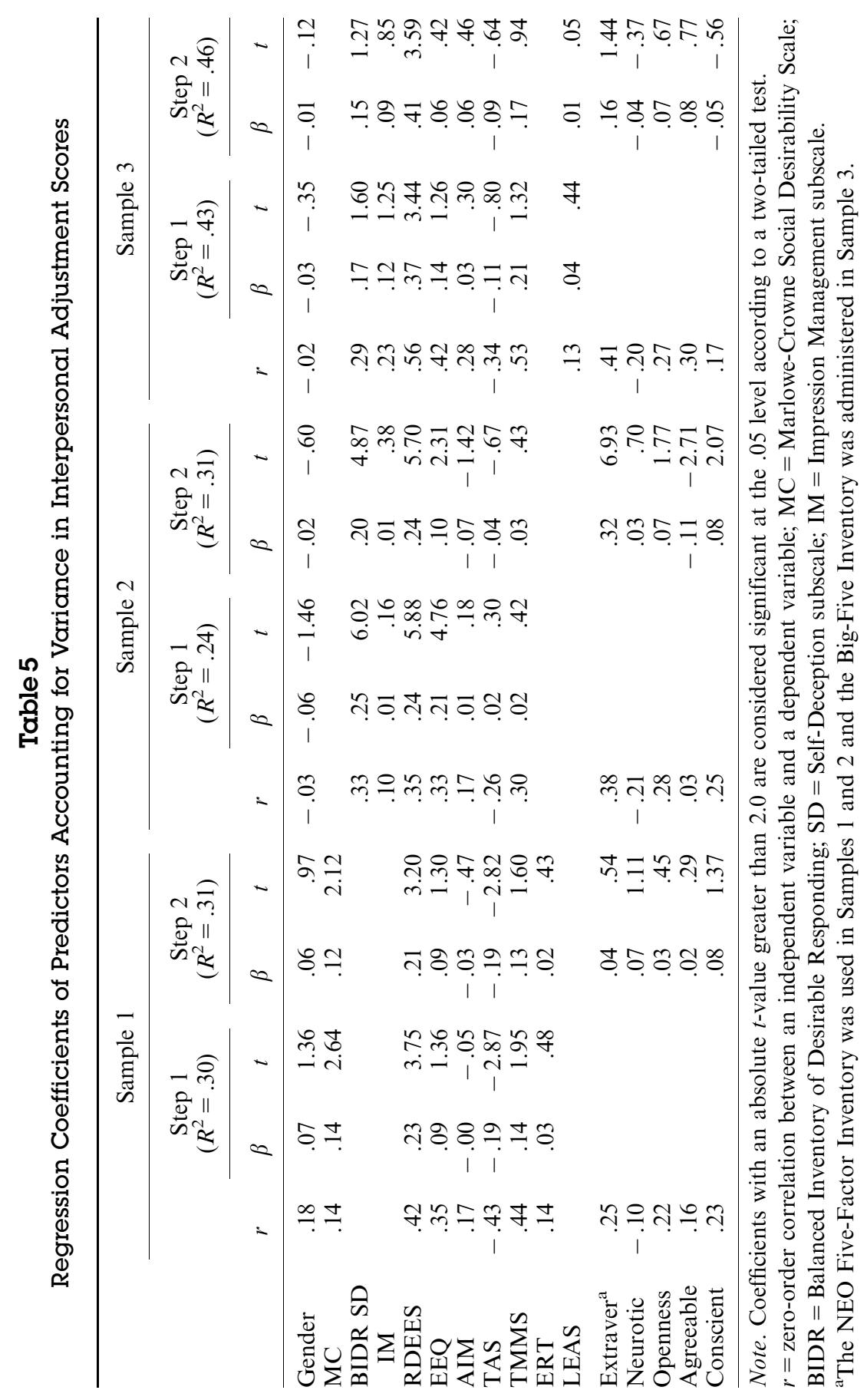


interpreted as meaning that scores on the interpersonal adaptability measure were affected in part by self-enhancing tendencies.

In the next step, we entered the Big Five personality variables to determine whether the RDEES would continue to account for variance in interpersonal adaptability once the personality variables were considered. Table 5 shows that the effect of the RDEES remained unchanged despite its correlation with Openness to Experience. Some of the personality variables were influential in certain situations. For example, the Extraversion scale in Sample 2 was the strongest single predictor of interpersonal adaptability. The Agreeableness and Conscientiousness scales also emerged as important predictors in Sample 2. However, those effects were not replicated with other outcome variables and in other samples.

We conducted another set of hierarchical regression analysis by replacing the RDEES with its two subscales. The overall results remained the same, but this analysis revealed that the explanatory power of the RDEES with respect to interpersonal adaptability stemmed mainly from the Differentiation subscale $(\beta \mathrm{s}=.40, .24, .39$ with $t=3.41,5.59,4.36$, in the first step). The effect sizes for the Range subscale were weak $(\beta \mathrm{s}=.09, .05, .09$ with $t=1.51,1.19, .88)$, although its zero-order correlations with outcome variables were not negligible $(r \mathrm{~s}=.28, .23, .23)$. This implies that the unique variance explained by the Range subscale was limited when other emotion variables were included in the regression equation. The standardized regression coefficients for the Differentiation and Range subscales were not much changed after the personality variables were introduced in the second step.

Finally, the third set of hierarchical regression analysis was conducted by substituting the TAS and the TMMS with their subscales to check whether the results would remain the same. The Differentiation subscale emerged as the only predictor that significantly accounted for variance in the outcome variables across the three samples. ${ }^{4}$ The results from the three hierarchical regression analyses suggest that the RDEES (especially its Differentiation subscale)

4. One reviewer suggested that we should test a possible interaction effect between emotional complexity and gender on interpersonal adaptability. Following the suggestion, we re-ran the hierarchical regression analysis by including the interaction term between the RDEES and gender. No statistically meaningful interaction effects were found across the three different samples. 
was superior to other emotion measures in accounting for variance in interpersonal adaptability, even after other emotion constructs, personality, and social desirability were controlled. This result was robust across three different samples and three outcome measures.

In summary, the hypotheses were all supported. Individuals with higher RDEES scores were more privately self-conscious, open to experience, empathic toward others, and interpersonally adaptable. Although Study 1 provided promising evidence for the construct validity of the RDEES, it was limited to self-reported measures. More convincing construct validity could be established if non-selfreport measures were used. This was the main goal of the second study.

\section{Study 2}

In Study 2, we obtained peer ratings on the RDEES, measured the number of emotion categories used by study participants to subdivide the emotion domain, and collected daily mood reports for 3 weeks. Peer ratings are often considered a gold standard for validating a new individual-differences instrument (Paulhus \& Martin, 1988), but depending on the nature of the construct, peer ratings are not always a suitable method for validation (Funder \& Debroth, 1987). We thought peer ratings would be an appropriate method for establishing the validity of the Range subscale of the RDEES because peers can presumably see some of the differences in a person's varied emotional states. However, peers might not be as good at detecting differences in emotional differentiation, because much of this process is purely subjective. In other words, experiencing a wide range of emotions is likely to be evident in verbal or nonverbal expressions, whereas experiencing subtle differences between similar emotions may not be observable by other people. By this reasoning, self-peer agreement was expected to be substantial only on the Range subscale.

Measuring the number of emotional categories a person uses to characterize emotion terms was employed to establish the validity of the RDEES's Differentiation subscale. In a situation where participants are asked to sort emotion words based on their similarities, people who are high on emotion differentiation should generate more emotion categories, based on making finer distinctions. Although the range of emotional experience might also play a part in 
generating emotion categories, we expected emotional differentiation to be the main determinant of categorization complexity.

Daily mood reports were used to determine whether individuals high on the RDEES tend to experience more varied and differentiated emotions on a daily basis. We expected that both aspects of emotional experience - Range and Differentiation - would contribute to experiencing and reporting variations in daily mood.

We were also interested in exploring a different measure of interpersonal adaptability because the measures used in Study 1 were based on self-reports that could have been unduly influenced by subjective bias. Peer reports on interpersonal relationships were collected for this purpose. Study 1 showed that the Differentiation subscale played a crucial role in the hierarchical regression analysis predicting interpersonal adaptability, although the two subscales of the RDEES had highly similar relationships with other emotion and personality measures. We explored whether the same pattern would replicate with peer reports about interpersonal relationships. Finally, the association between emotional complexity and cognitive complexity was tested to discover whether having varied and differentiated emotional experience is related to cognitive complexity, as previous research suggested.

The major hypotheses were as follows: (1) The construct validity of the RDEES and its two subscales would be supported by significant self-peer agreement, the average number of emotions checked on the daily mood scale, and the number of emotion categories generated when sorting emotion names; (2) The RDEES, especially the Differentiation subscale, would be positively correlated with a selfreport measure of interpersonal relationship quality and its peer equivalent; (3) The RDEES would be positively associated with a measure of cognitive complexity.

\section{METHOD}

\section{Participants}

Ninety-five students who were taking various psychology courses were recruited with fliers distributed in those courses. Participants received 3 hours of course credit for taking part in the 2-month research project. Two students (one man and one woman) did not complete the final questionnaires, and the woman also failed to complete the emotion card-sorting 
task. Because they followed through with the entire procedure except for those components, their data were included in most of the analyses. The 95 participants ranged in age from 18 to 26 , with a mean of 19.3 years $(S D=1.45)$; there were 17 men; 51 participants were European American (54\%) and 35 were Asian American (37\%).

\section{Procedure}

After students decided to take part in the study, they were asked to provide the names, addresses, and telephone numbers of five people who knew them very well. All participants completed a questionnaire packet in a small group setting (10 to 20 people) during the first week of the study. Starting the following week, they participated in an individual session for "sorting emotion cards." Then, all reported their daily mood for 21 consecutive days. After all individual card-sorting sessions and daily mood reports were completed, the participants filled out another questionnaire packet at the debriefing session.

\section{Measures}

Besides the RDEES (rated on a 5-point rating scale), the Balanced Inventory of Desirable Responding (BIDR), and the Interpersonal Relationship Quality scale (IRQ), several new measures assessing cognitive complexity and psychological health were included in Study 2.

Cognitive complexity. Sommers (1981) used descriptions of others (Peevers \& Secord, 1973) as a measure of cognitive complexity, whereas Lane and his colleagues (1990) employed the Sentence Completion Test (SCT; Hy \& Loevinger, 1996). We chose the SCT not only because it can serve as a proxy measure of cognitive complexity but also because it can assess different levels of ego development and maturity. The SCT consists of 36 items; scoring was based on the guide developed by Hy and Loevinger (1996). Two raters, blind to the hypothesis and participants' scores on the RDEES, were trained to score the items independently. Percentage agreement for the 36 items ranged from $62 \%$ to $98 \%(M=81 \%, S D=10 \%)$. All disagreements were resolved by discussion. Total protocol ratings (TPR) were derived from these individual item scores following the automatic ogive rules in Hy and Loevinger's scoring manual (1996, p. 39). In the present study, TPR scores ranged from 3 (self-protective level) to 7 (individualistic level) with a mode of 6 (conscientious level). Due to the restricted range of the TPR scores, we computed the total item score as well. It ranged from 149 to $216(M=183.59, S D=13.50)$.

Psychological health. Although there was no association between the RDEES and the neuroticism scale in Study 1, we were interested in replicating that result with another mental health scale. The revised version 
of the Symptom Check List-90 (SCL-90-R; Derogatis, 1989) was selected for this purpose. There were nine primary subscales: somatization, obsessive-compulsion, inferiority, depression, anxiety, hostility, phobic anxiety, paranoid ideation, and psychoticism. There was also a Global Severity Index (GSI) - a total of the scale scores representing an individual's overall level of psychopathology.

Peer ratings. A copy of a questionnaire containing the RDEES and the IRQ was mailed to the five people named on each participant's list; a stamped return envelope was provided. These people rated their friend/ relative on the RDEES and the IRQ from their perspective. The total number of peers responding was 347 (the number per subject ranged from 2 to 5 , with $M=3.69, S D=.98$ ). One subject had no peers responding and was therefore eliminated from the peer-rating analyses. Of the individuals who completed and returned the peer questionnaire, $63 \%$ were friends, $31 \%$ were family members and significant others, and $6 \%$ did not specify the nature of their relationship.

Daily mood reports. Subjects reported their moods for 3 weeks using the 20-item Positive Affect and Negative Affect Schedule (PANAS; Watson et al., 1988). They submitted reports every night, via either the Internet or the telephone. If they used a computer, they logged on to a Web site and completed the PANAS; if they used a phone, they called a voice mail number and read their ratings on all 20 items. Sixty percent of the subjects exclusively used the Internet method for 3 weeks. ${ }^{5}$

Two different indicators of emotional experience were created, based on the daily mood reports: Total Emotion and Mood Variability. A Total Emotion score was generated by counting the average number of different emotions the participants experienced per day over 21 days. Since the PANAS is rated on a 5-point scale, we counted the number of emotions that the subjects marked 2 ("a little") or higher. Two subscale scores, Positive and Negative Emotion, were also generated. A Mood Variability score was formed by computing the average within-participant standard deviation, an index of the average degree of mood fluctuation over time. As in the case of the Total Emotion score, three variability summary scores were created - Overall, Positive, and Negative Mood Variability. Sorting emotion cards. This method was originally used by Shaver et al., (1987). Participants were asked to sort 135 cards, each of which contained the name of an emotion (e.g., anger, affection, surprise, fear). The 135 emotion words were the ones that Shaver et al.'s study participants were most certain named emotions. In our individual sessions, participants were instructed to sort the cards into groups (piles) containing "similar

5. We checked for mood differences between the two groups - those using a computer and those using the telephone. There was no difference. 
emotions." The number of categories varied from 2 to 59 and will be used here as an alternative measure of emotional differentiation.

\section{RESULTS AND DISCUSSION}

\section{Structure of the RDEES}

We began by checking the scale properties of the RDEES. There were three sets of RDEES scores in Study 2-one for the initial RDEES administration, one for the follow-up administration, and one for the peer ratings. To cross-validate the structure of the RDEES, three second-order confirmatory factor analyses were performed using LISREL 8. Based on the two-factor structure found in Study 1, we specified a model in which seven items loaded only on the Range factor, the other seven items loaded only on the Differentiation factor, and one general factor lay behind the two first-order factors. Fit indexes showed that this model was acceptable for all three analyses $(\mathrm{NNFI}=0.92,0.94,0.93 ; \mathrm{CFI}=0.93,0.95,0.95$; and $\mathrm{RMSEA}=.06$, $.07, .06)$. This two factor-model significantly improved the model fit compared to a one-factor model $\left(\Delta \chi^{2}=140.35,205.51,165.47\right.$ with $\Delta d f=1, p<.001)$. The 6-week temporal consistency of the RDEES was .77. In short, the RDEES has very good psychometric properties despite its brevity and ease of administration.

Table 2 displays the means and standard deviations of the RDEES by gender (all correlations reported in Study 2 were based on the initial administration of the RDEES). Women and European Americans tended to have higher RDEES scores than men and Asian Americans, but the differences were small. ${ }^{6}$ Finally, when the correlations between the RDEES and the two subscales of the BIDR were examined, they were .07 for impression management $(r=-12$. for the Range subscale and $r=.25$ for the Differentiation subscale) and .02 for self-deception $(r=-.16$ for the Range subscale and $r=.21$ for the Differentiation subscale).

6. Gender differences in the mean scores of all measures used in Study 2 were examined due to a highly unbalanced gender composition ( 17 men vs. 78 women) in this sample. The results of t-test revealed that women were perceived to have more broad range of emotional experiences then men by their peers on the peerrated Range subscale scores (3.45 vs. 3.73) and reported fewer average number of negative emotional experience than men on daily mood reports (5.05 vs. 3.06). Besides these two scores, no gender differences were found. 


\section{Construct Validity of the RDEES}

The top part of Table 6 displays correlations between the RDEES and measures included to test its construct validity. The peer-self agreement on the RDEES was moderate but significant $(r=.29)$, which seems acceptable, considering the nature of the construct assessed by the RDEES (John \& Robins, 1993). Self-peer agreement on the Range subscale was substantial $(r=.41)$, confirming our speculation that emotional range would be at least somewhat observable from the outside. In contrast, the self-peer correlation for the Differentiation subscale was only .12.

The construct validity of the Differentiation subscale was supported by the card-sorting task. We expected individuals with higher Differentiation scores to generate more emotion categories, and they did: $r=.33$. The Differentiation subscale had a somewhat stronger association with the number of categories than did the Range subscale $(r=.20)$. This finding implies that differentiation of emotional experience is more relevant to producing fine-grained emotion categories than the range of emotional experience.

The correlation of the RDEES with the Total Emotion score based on daily mood reports was .27, supporting the hypothesis that individuals who score higher on the RDEES tend to experience more emotions on a daily basis than individuals who score lower. The correlation was slightly higher for negative than for positive emotions ( $r=.26$ vs. $r=.19)$. The RDEES was also positively correlated with Mood Variability $(r=.24$ overall; $r=.25$ for Positive Mood Variability and .17 for Negative Mood Variability). These results imply that individuals with high RDEES scores tend to experience both emotional diversity and emotional variability.

\section{Interpersonal Relationship Quality}

Another aim of Study 2 was to determine whether individuals scoring relatively high on the RDEES have warm and comforting relationships with others, as judged by peers, an issue not explored in Study 1 . We were also interested in determining whether the Differentiation subscale would have a stronger association with peer reports about interpersonal relationships than the Range subscale, replicating the findings in Study 1. As can be seen in Table 6, the correlations between the RDEES and both self-reported and peerrated Interpersonal Relationship Questionnaire scores indicate that 


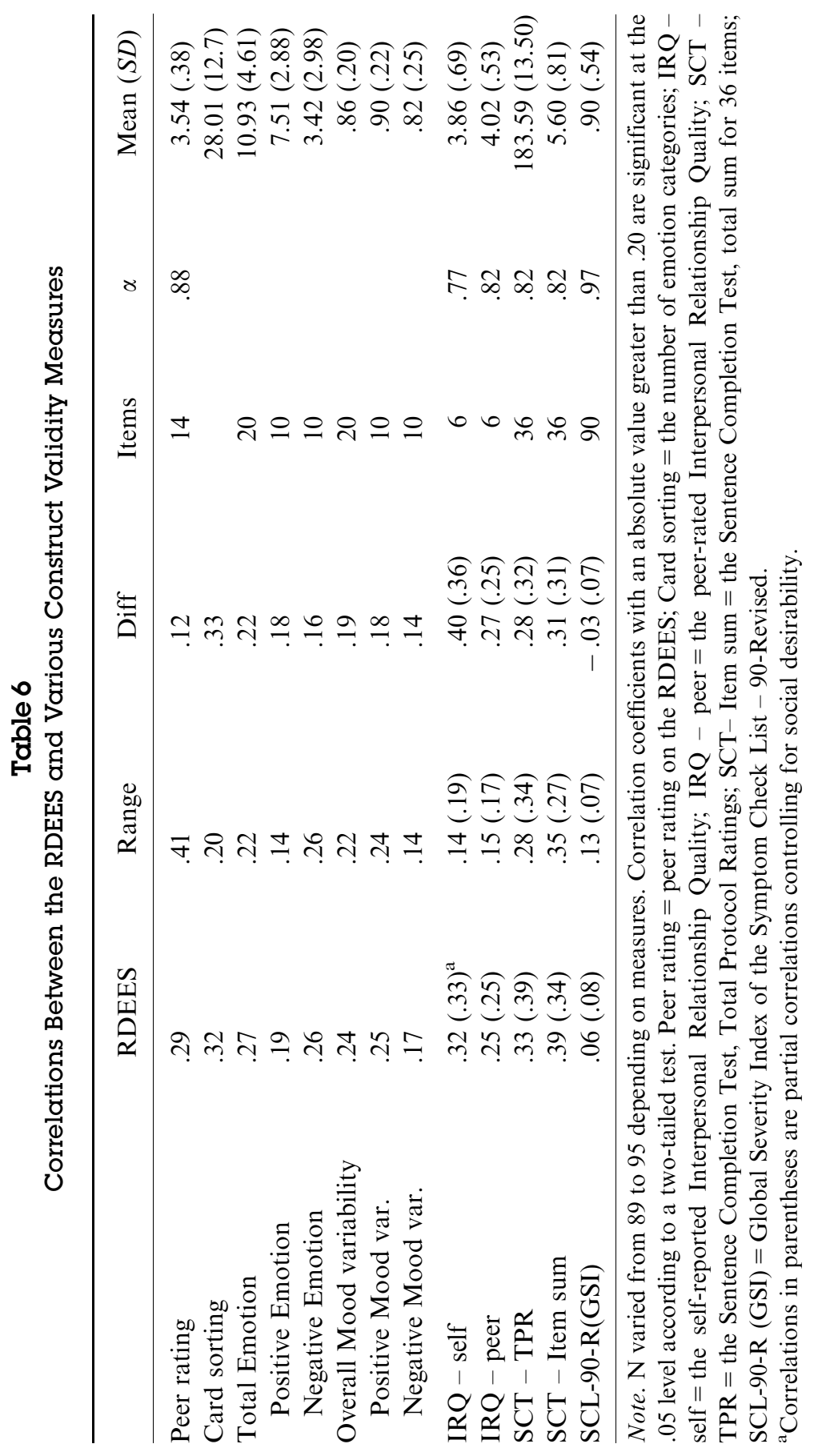


people with higher RDEES scores have higher quality relationships $(r=.32$ for the self-reported IRQ, .25 for the peer-rated IRQ). Replicating the findings in Study 1, the Differentiation subscale $(r=.40$ for the self-reported IRQ, .27 for the peer-rated IRQ) was more involved in this association than the Range subscale $(r=.14$ for the self-reported IRQ, .15 for the peer-rated IRQ). This overall picture of the associations among the measures remained the same after controlling for the influence of social desirability. These results suggest that emotional differentiation is more important than emotional range for maintaining good relationships.

\section{Cognitive Complexity and Neuroticism}

Previous research (Lane \& Schwartz, 1987, 1992; Sommers, 1981) implied that having broad and differentiated emotional experience is related to cognitive complexity. We were able to confirm this association. Table 6 displays the correlations between the RDEES and two scores from the Sentence Completion Test (SCT): Total Protocol Rating (TPR) and total item score. Both correlations were moderately strong ( $r=.33$ for the TPR and .39 for the total item score), and maintained their effect sizes when social desirability was controlled. These effect sizes cannot be accounted for by method variance because the RDEES is a self-report scale, whereas the SCT is an open-ended test. The two subscales of the RDEES contributed almost equally to its correlation with the two SCT summary scores.

Finally, we examined correlations between the RDEES and the 10 scores ( 9 subscale scores and the Global Severity Index) from the revised Symptom Check List -90 . None of the 10 scores was related to the RDEES, replicating the lack of association with neuroticism in Study 1.

\section{GENERAL DISCUSSION}

Two studies were conducted to explore the psychological characteristics and implications of emotional complexity. The results supported all of our hypotheses: Individuals with varied and welldifferentiated emotional experience were more attentive to their inner feelings and thoughts, open to experience, and cognitively complex. Equally important, individuals high on the RDEES showed empathic concern for others' feelings and were more adaptable in 
interpersonal interactions. Range and differentiation of emotional experience are not the same as emotional expressiveness, emotional intensity, or (low) alexithymia, although they are related to all three. Emotional range and differentiation are not reducible to the Big Five personality traits, although they are related to Openness to Experience.

\section{Significance and Implications}

This research empirically demonstrates an association between emotional complexity and interpersonal adaptability. Emotion researchers have suggested that one function of emotion is to guide adaptation to the social environment (e.g., Buck, 1984; Izard, 1991). In an attempt to explain how emotion specifically helps people adjust in social situations, many researchers have focused on emotional expression and its role in communication (see Planalp, 1999, for a review), but few studies have explored the relationship between emotional complexity and interpersonal behavior (Lane, 2000). To our knowledge, the present study provides the first empirical evidence that individual differences in the range and differentiation of emotional experience are related to greater interpersonal adaptability. The results of the hierarchical regression analysis conducted in Study 1 suggest the importance to social interaction of having well-differentiated emotional experience as a guide. Even after controlling for social desirability bias, personality, and other emotion variables, interpersonal adaptability was mainly explained by the RDEES. Because all of the measures of adaptability used in Study 1 were based on self-report, we collected peer ratings of interpersonal relationship quality in Study 2. The results showed that peers notice that individuals with emotional complexity maintain good, warm relationships with others.

Among the subscales of the RDEES, the Differentiation subscale was the major force behind the association between the RDEES and interpersonal adaptability. When other emotion variables were considered simultaneously, the effect of the Range subscale on interpersonal adaptability disappeared. Emotional differentiation was also more strongly associated than emotional range with both selfand peer ratings of interpersonal relationship quality. Although the two aspects of emotional complexity were substantially related, as we expected and intended (factor correlations ranged from .42 to 
$.57)$, and their correlations with other emotion and personality variables appeared similar, they were distinct in their relationships with interpersonal adaptability. Discovering precisely why emotional differentiation is beneficial to maintaining good interpersonal relationships is a task for future studies, but we can provide some initial clues.

We noticed that the Differentiation subscale was more strongly associated than the Range subscale with knowing about ones' own feelings in Study 1. The results of factor analyses of emotion-related variables also revealed that the Differentiation subscale loaded on both emotional experience and recognition factors. As we speculated earlier, knowing one's own feelings may help with understanding others' feelings (Saarni, 1997). It may also help one decide how best to behave in interpersonal situations. In contrast, the Range subscale was more strongly correlated with emotional intensity (Study 1) and mood variability (Study 2). Although experiencing intense and varied moods could be part of emotional complexity, these qualities may not contribute to maintaining good interpersonal relationships.

The present study also empirically demonstrated that emotional complexity is associated with ego development. This finding suggests that gaining varied and differentiated emotional experience is a psychosocial-developmental achievement, an aspect of ego maturity. Emotion theorists have posited that one of the defining characteristics of emotional maturity is differentiation (De Rivera, 1984; Malatesta \& Izard, 1984), because differentiation is considered a major process of development (Cartensen et al., 2000; Werner, 1940). However, the connection between emotional differentiation and ego development had not been demonstrated empirically. The present results suggest that emotional complexity is part of ego maturity, and our research helps explain why ego development is related to interpersonal adaptability. Several researchers have demonstrated that level of ego development is related to interpersonal adjustment (Helson \& Wink, 1987; White, 1985). Individual differences in emotional complexity may be one of the links between ego maturity and interpersonal adjustment.

A mystery emerging from our studies is that the RDEES is unrelated to neuroticism and the Symptom Check List-90. These results indicate, roughly speaking, that there are two different kinds of individuals with complex emotional experience: those who are emotionally complex and also somewhat neurotic and those who have a 
similar degree of emotional complexity, but are psychologically healthy. We suspect that emotional integration is one factor that can distinguish between these two kinds of emotional complexity. It has been argued that differentiation and effectiveness of integration are independent in general (Witkin, Goodenough, \& Oltman, 1979). One way to assess the effectiveness of integration would be to investigate how individuals regulate their emotions. In this regard, Feldman Barrett and her colleagues (2001) explored a relation between emotion differentiation and emotion regulation. It was hypothesized and observed that emotion differentiation and emotion regulation were positively related only when intense negative emotions were experienced. It will be intriguing in future studies to learn more about these seemingly different kinds of emotionally varied and well-differentiated individuals and their skills at emotion regulation.

\section{Potential Limitation and Future Directions}

Although we have provided extensive preliminary evidence for the construct validity of the RDEES in the present study, it will still be desirable in future studies to establish additional ties to behavioral measures. One possibility, which we are pursuing, would be to see whether high scorers on the RDEES - especially the Differentiation subscale - are better judges of facial expressions of emotions displayed by interaction partners in short video clips. If high scorers are better not only at noticing and understanding their own feelings, but also at decoding the highly variable emotional expressions of others, this would provide one stepping-stone to understanding why having differentiated emotional experience would be beneficial to maintaining good interpersonal relationships.

Another possible limitation of this study is that the relation between emotional complexity and cognitive complexity was not rigorously explored. The measure of cognitive complexity in the present study was the Sentence Completion Test, which reflects different levels of cognitive sophistication. This measure may not directly assess sensitivity to subtle differences in every aspects of life. Given the abstract nature of some of the items in the RDEES, it could be argued that the scale actually measures a generally differentiated cognitive style rather than emotional complexity. However, based on this argument, it would be difficult to explain why the RDEES is 
substantially correlated with the measures of empathy and interpersonal adaptability. Nevertheless, it will be desirable in future studies to establish the discriminant validity of emotional complexity as distinct from other forms of cognitive complexity.

Finally, the relation between self-reported emotional complexity and actual abilities in this domain needs to be explored further, although the present study provided some preliminary evidence for the association between the RDEES and non-self-report measures of emotional complexity. The correlations of the RDEES with the Levels of Emotional Awareness Scale (LEAS) and the Emotional Range Test (ERT) were .30 and .20 , respectively. The magnitude of those correlations was not large, but they are meaningful because the LEAS and the ERT require open-ended responses. The RDEES was also related to the number of emotion categories generated by study participants when they sorted emotion words. These results support the construct validity of the RDEES, but they should be supplemented by additional objective measures of emotional complexity such as variability in expressed emotions and greater ability to articulate the differences between similar emotional states.

\section{Closing Remarks}

In summary, we have shown that it is possible, at least in college samples, to measure range and differentiation of emotional experience in a simple, direct, and reliable way. The RDEES promises to be a valuable addition to the growing array of individual-difference measures related to emotional experience and expression. It taps an important construct - an aspect of emotional experience that is related to emotional maturity and success in relationships. Varied and differentiated emotional experience, like crystallized intelligence (Cattell, 1963), may be one of the components of ego maturity that improves with age rather than declines. If there is such a thing as social or emotional intelligence, varied and well-differentiated emotional experience is likely to be one of its important components.

\section{REFERENCES}

Bagby, R. M., Parker, J. D. A., \& Taylor, G. J. (1994). The twenty-item Toronto Alexithymia Scale: I. Item selection and cross-validation of the factor structure. Journal of Psychosomatic Research, 38, 23-32. 
Ben-Artzi, E., \& Mikulincer, M. (1995). Lay theories of emotion: 3. The intraindividual structure of emotions. Imagination, Cognition, and Personality, 15, 321-336.

Buck, R. (1984). The communication of emotion. New York: Guilford Press.

Carstensen, L. L., Pasupathi, M., Mayr, U., \& Nesselroade, J. R. (2000). Emotional experience in everyday life across the adult life span. Journal of Personality and Social Psychology, 79, 644-655.

Cattell, R. B. (1952). P-technique factorization and the determination of individual dynamic structure. Journal of Clinical Psychology, 8, 5-10.

Cattell, R. B. (1963). Theory of fluid and crystallized intelligence: A critical experiment. Journal of Educational Psychology, 54, 1-22.

Clore, G. L., Ortony, A., \& Foss, M. A. (1987). The psychological foundation of the affective lexicon. Journal of Personality and Social Psychology, 53, 751-766.

Costa, P. T. Jr., \& McCrae, R. R. (1989). The NEO-PI/FFI manual supplement. Odessa, FL: Psychological Assessment Resources.

Cronbach, L. J., \& Meehl, P. E. (1955). Construct validity in psychological test. Psychological Bulletin, 52, 281-302.

Davis, M. (1980). A multidimensional approach to individual differences in empathy. JSAS Catalog of Selected Documents in Psychology, 10, 85.

Darwin, C. (1872/1965). The expression of the emotions in man and animals. Chicago: University of Chicago Press.

De Rivera, J. (1984). Development and the full range of emotional experience. In C. Z. Malatesta \& C. E. Izard (Eds.), Emotion in adult development (pp. 45-64). Beverly Hills, CA: Sage.

Derogatis, L. R. (1989). Description and bibliography for the SCL-90-R and other instruments of the psychopathology rating scale series. Riderwood, MD: Clinical Psychometric Research, Inc.

Ekman, P., \& Friesen, W. V. (1975). Unmasking the face: A guide to recognizing emotions from facial cues. Englewood Cliffs, NJ: Prentice-Hall.

Feldman, L. A. (1995). Valence focus and arousal focus: Individual differences in the structure of affective experience. Journal of Personality and Social Psychology, 69, 153-166.

Feldman Barrett, L. (1998). Discrete emotions or dimensions?: The role of valence focus and arousal focus. Cognition and Emotion, 12, 579-599.

Feldman Barrett, L., Gross, J., Chirstensen, T. C., \& Benvenuto, M. (2001). Knowing what you're feeling and know what to do about it: Mapping the relation between emotion differentiation and emotion regulation. Cognition and Emotion, 15, 713-724.

Feldman Barrett, L., Lane, R. D., Sechrest, L., \& Schmartz, G. E. (2000). Sex differences in emotional awareness. Personality and Social Psychology Bulletin, 26, 1027-1035.

Feldman Barrett, L., \& Russell, J. A. (1998). Independence and bipolarity in the structure of current affect. Journal of Personality and Social Psychology, 74, 967-984.

Fenigstein, A. (1997). Self-consciousness and its relation to psychological mindedness. In M. McCallum \& W. E. Piper (Eds.), Psychological mindedness: A 
contemporary understanding (pp. 105-131). Mahwah, NJ: Lawrence Erlbaum Associate, Inc.

Fenigstein, A., Scheier, M. F., \& Buss, A. H. (1975). Public and private self-consciousness: Assessment and theory. Journal of Personality Assessment, 43, $522-527$.

Foster, P. S., Webster, D. G., \& Smith, E. W. L. (1997). The psychophysiological differentiation of emotional memories. Imagination, Cognition, and Personality, 17, 111-122.

Freedman, M. B., \& Sweet, B. S. (1954). Some specific features of group psychotherapy and their implications for selection of patients. International Journal of Group Psychotherapy, 4, 355-368.

Funder, D. C., \& Debroth, K. M. (1987). Differences between traits: Properties associated with interjudge agreement. Journal of Personality and Social Psychology, 52, 409-418.

Helson, R., \& Wink, P. (1987). Two conceptions of maturity examined in the findings of a longitudinal study. Journal of Personality and Social Psychology, 53, 531-541.

Hy, L. X., \& Loevinger, J. (1996). Measuring ego development (2nd ed). Mahwah, NJ: Erlbaum.

Izard, C. E. (1991). The psychology of emotions. New York: Plenum Press.

John, O. P., \& Robins, R. W. (1993). Determinants of interjudge agreement on personality traits: The Big Five domains, observability, evaluativeness, and the unique perspective of the self. Journal of Personality, 61, 521-551.

John, O. P., \& Srivastava, S. (1999). The Big Five trait taxonomy: History, measurement, and theoretical perspectives. In L. A. Pervin \& O. P. John (Eds.), Handbook of personality: Theory and research (pp. 102-138). New York: Gilford.

King, L. A., \& Emmons, R. A. (1990). Conflict over emotional expression: Psychological and physical correlates. Journal of Personality and Social Psychology, 58, 864-877.

Kitayama, S., \& Markus, H. (Eds.). (1994). Emotion and culture: Empirical studies of mutual influence. Washington, DC: American Psychological Association.

Lane, R. D. (2000). Levels of emotional awareness: Neurobiological, psychological, and social perspectives. In R. Bar-On \& J. D. A. Parker (Eds.), The handbook of emotional intelligence (pp. 363-388). San Francisco: Jossey-Bass/ Pfeiffer.

Lane, R. D., Quinlan, D. M., Schwartz, G. E., Walker, P. A., \& Zeitlin, S. B. (1990). The Levels of Emotional Awareness Scale: A cognitive-developmental measure of emotion. Journal of Personality Assessment, 55, 124-134.

Lane, R. D., \& Schwartz, G. E. (1987). Levels of emotional awareness: A cognitive-developmental theory and its application to psychopathology. American Journal of Psychiatry, 144, 133-143.

Lane, R. D., \& Schwartz, G. E. (1992). Levels of emotional awareness: Implications for psychotherapeutic integration. Journal of Psychotherapy Integration, 2, 1-18.

Lane, R. D., Sechrest, L., \& Riedel, R. (1998). Sociodemographic correlates of alexithymia. Comprehensive Psychiatry, 39, 377-385. 
Lane, R. D., Sechrest, L., Reidel, R., Weldon, V., Kaszniak, A., \& Schwartz, G. E. (1996). Impaired verbal and nonverbal emotion recognition in alexithymia. Psychosomatic Medicine, 58, 203-210.

Larsen, R. J. (1987). The stability of mood variability: A spectral analytic approach to daily mood assessment. Journal of Personality and Social Psychology, 52, 1195-1204.

Larsen, R. J., \& Cutler, S. E. (1996). The complexity of individual emotional lives: A within-subject analysis of affect structure. Journal of Social and Clinical Psychology, 15, 206-230.

Larsen, R. J., Diener, E., \& Emmons, R. A. (1986). Affect intensity and reactions to daily life events. Journal of Personalit y and Social Psychology, 51, 803-814.

Levenson, R. W. (1992). Autonomic nervous system differences among emotions. Psychological Science, 3, 23-27.

Lennox, R. D., \& Wolfe, R. N. (1984). Revision of the Self-Monitoring Scale. Journal of Personality and Social Psychology, 46, 1349-1364.

Lewis, M. (1993). The emergence of human emotions. In M. Lewis \& J. M. Haviland (Eds.), Handbook of emotion (pp. 223-236). New York: Guilford Press.

Linden, W., Wen, F., \& Paulhus, D. (1995). Measuring alexithymia: Reliability, validity, and prevalence. In J. N. Butcher \& D. Spielberger (Eds.), Advances in personality assessment (Vol. 10, pp. 51-95). Hillsdale, NJ: Erlbaum.

Lopez, F. G., Gover, M. R., Leskela, J., Sauer, E. M., Schirmer, L., \& Wyssmann, J. W. (1997). Attachment styles, shame, guilt, and collaborative problemsolving orientation. Personal Relationships, 4, 187-199.

Lumley, M. A., Stetter, L., \& Wehmer, F. (1996). How are alexithymia and physical illness linked? A review and critique of pathways. Journal of Psychosomatic Research, 41, 505-518.

Malatesta, C. Z., \& Izard, C. E. (1984). Emotion in adult development. Sage: Beverly Hills, CA.

Marlowe, D., \& Crowne, D. D. (1964). The approval motive: Studies in evaluative dependence. New York: Wiley.

Mayer, J. D., Caruso, D. R., \& Salovey, P. (2000). Emotional intelligence meets traditional standards for an intelligence. Intelligence, 27, 267-298.

Mayer, J. D., \& Salovey, P. (1997). What is emotional intelligence? In P. Salovey \& D. J. Sluyter (Eds.), Emotional development and emotional intelligence: Educational implications (pp. 3-34). New York: Basic Books.

McCrae, R. R., \& Costa, P. T. (1997). Conceptions and correlates of openness to experience. In R. Hogan, J. Johnson, \& S. Briggs (Eds.), Handbook of Personality (pp. 825-847). San Diego: Academic Press.

Nemiah, J. C., \& Sifneos, P. E. (1970). Affect and fantasy in patients with psychosomatic disorder. In O. W. Hill (Ed.), Modern trends in psychosomatic medicine (Vol. 2, pp. 26-35). New York: Appleton-Century-Crofts.

Paulhus, D. L. (1984). Two component models of socially desirable responding. Journal of Personality and Social Psychology, 46, 598-609.

Paulhus, D. L., \& Martin, C. L. (1987). The structure of personality capabilities. Journal of Personality and Social Psychology, 52, 354-365. 
Paulhus, D. L., \& Martin, C. L. (1988). Functional flexibility: A new conception of interpersonal flexibility. Journal of Personality and Social Psychology, 55, 88-101.

Peevers, H. G., \& Secord, F. P. (1973). Developmental changes in attribution of descriptive concepts to persons. Journal of Personality and Social Psychology, 27, 120-129.

Piaget, J. (1962). The stages of the intellectual development of the child. Bulletin of the Menninger Clinic, 26, 120-128.

Planalp, S. (1999). Communicating emotion: Social, moral, and cultural processes. Cambridge: Cambridge University Press.

Russell, J. A. (1995). Facial expressions of emotion: What lies beyond minimal universality? Psychological Bulletin, 118, 379-391.

Saarni, C. (1997). Emotional competence and self-regulation in childhood. In P. Salovey \& D. J. Sluyter (Eds.), Emotional development and emotional intelligence: Educational implications (pp. 35-66). New York: Basic Books.

Salovey, P., \& Mayer, J. D. (1990). Emotional intelligence. Imagination, Cognition, and Personality, 9, 185-211.

Salovey, P., Mayer, J. D., Goldman, S. L., Turvey, C., \& Palfai, T. P. (1995). Emotional attention, clarity, and repair: Exploring emotional intelligence using the Trait Meta-Mood Scale. In J. W. Pennebaker (Ed.), Emotion, disclosure, and health (pp. 125-154). Washington, DC: American Psychological Association.

Shaver, P., Schwartz, J., Kirson, D., \& O'Connor, C. (1987). Emotion knowledge: Further exploration of a prototype approach. Journal of Personality and Social Psychology, 52, 1061-1086.

Sifneos, P. E. (1973). The prevalence of alexithymic characteristics in psychosomatic patients. Psychotherapy and Psychosomatics, 22, 255-262.

Sommers, S. (1981). Emotionality reconsidered: The role of cognition in emotional responsiveness. Journal of Personality and Social Psychology, 41, $553-561$.

Sommers, S., \& Scioli, A. (1986). Emotional range and value orientation: Toward a cognitive view of emotionality. Journal of Personality and Social Psychology, 51, 417-422.

Stemmler, G. (1992). The vagueness of specificity: Models of peripheral physiological emotion specificity in emotion theories and their experimental discriminability. Journal of Psychophysiology, 6, 17-28.

Taylor, G. J., Bagby, R. M., \& Parker, J. D. A. (1991). The alexithymia construct: A potential paradigm for psychosomatic medicine. Psychosomatics, 32, $153-164$.

Tobacyk, J. (1981). Personality differentiation, effectiveness of personality integration, and mood in female college students. Journal of Personality and Social Psychology, 41, 348-356.

Watson, D., \& Tellegen, A. (1985). Toward a consensual structure of mood. Psychological Bulletin, 98, 219-235.

Watson, D., Clark, L. A., \& Tellegen, A. (1988). Development and validation of a brief measure of positive and negative affect: The PANAS scales. Journal of Personality and Social Psychology, 54, 1063-1070. 
Werner, H. (1940). The comparative psychology of mental development. New York: Harper \& Row.

Wessman, A., \& Ricks, D. (1966). Mood and personality. New York: Holt, Rinehart, \& Winston.

White, M. S. (1985). Ego development in adulthood. Journal of Personality, 53, 561-574.

Witkin, H. A., Goodenough, D. R., \& Oltman, P. K. (1979). Psychological differentiation: Current status. Journal of Personality and Social Psychology, 37, $1127-1145$.

Zevon, M. A., \& Tellegen, A. (1982). The structure of mood change: An ideographic/nomothetic analysis. Journal of Personality and Social Psychology, 43, 111-122.

Zhiyan, T., \& Singer, J. L. (1997). Daydreaming styles, emotionality, and the Big Five personality dimensions. Imagination, Cognition, and Personality, 16, 399-414. 